\title{
Non-Incisional Laparoscopic Left Nephrectomy With Abdomino-Perineal Resection for Synchronous Primary Tumors
}

\author{
Ivelin Takorov ${ }^{1}$ Tsvetan Trichkov $^{2, *}$ Maria Yakova $^{2}$ Radoslav Kostadinov ${ }^{2}$ \\ Vassil Mihaylov ${ }^{2}$ Nikola Vladov ${ }^{2}$ \\ ${ }^{1}$ First Department of Abdominal Surgery, Military Medical Academy, Sofia, \\ Bulgaria \\ ${ }^{2}$ HPB Surgery and Transplantology, Military Medical Academy, Sofia, Bulgaria \\ *Corresponding author: Tsvetan Trichkov, Sv. Georgi Sofiyski Street No.3, floor \\ 14, 1606 Sofia, Bulgaria. Tel: +359886501510; Fax: +35929225188; E-mail: \\ cvetantrichkov@gmail.com
}

DOI: $10.30699 /$ mci.5.2.482-1

Submitted: 14 November 2020

Revised: 21 January 2021

Accepted: 26 January 2021

e-Published: 17 March 2021

\section{Keywords:}

Colorectal Neoplasms

Kidney Neoplasms

Neoplasms, Multiple Primary

Laparoscopy
Introduction: Multiple synchronous neoplasms were first described in a study by Billroth in 1889. Since then, many researches have been conducted in this field till 1932 when Warren and Gates published their criteria for the diagnosis of two synchronous tumors. Synchronous colorectal and renal blastomas are rare. The number of case reports published so far is relatively small.

Case presentation: We report a case of a 63-years old male patient who was admitted to our clinic with symptomatic, histologically confirmed rectal adenocarcinoma located near the anorectal line. Contrast-enhanced CT showed evidence of synchronous lesion in the left kidney area. Laparoscopic left nephrectomy was performed, followed by abdominoperineal resection of the rectum with total mesorectal excision and para-aortic lymph dissection. Both resectates were extracted through the perineal access with no need for additional abdominal incision. No similar case was found in our literature review without using abdominal incision.

Conclusion: The simultaneous multi-visceral laparoscopic resection of synchronous neoplasms is a reliable and safe method in certain patients. When performed by an experienced surgical team, the oncological outcomes are comparable to those achieved; using a conventional approach. A specific advantage is that this is a one-stage surgery that provides quick recovery with lower risk of postoperative complications.

(C) 2021. Multidisciplinary Cancer Investigation

\section{INTRODUCTION}

Multiple synchronous neoplasms were first described in a publication by Billroth in 1889 [1]. Since then, different research has been conducted in this field till 1932 when Warren published his criteria for diagnosis of two synchronous tumours [2]. The laparoscopic approach has been established as a standard surgical procedure in the treatment of many diseases, including colorectal carcinoma. Many studies have shown the reliability and safety of this method [3]. Furthermore, the laparoscopic approach in synchronous intra-abdominal tumors has proven to be reliable, without increasing the rate of postoperative complications [4]. However, as there are very few documented cases of simultaneous laparoscopic resections in synchronous colorectal and renal neoplasms, no conclusions can be made on long-term oncological outcomes. 


\section{CASE PRESENTATION}

We report a case of a 63-years old male patient who underwent a diagnostic colonoscopy; resulting in detection of a tumor formation along almost the entire length of the rectum which was histologically confirmed to be a moderately differentiated adenocarcinoma. Preoperative contrast-enhanced CT detected a $55 \times 33 \mathrm{~mm}$ tumor formation in the left kidney area (Figure 1). The patient had no history of hereditary non-polyposis colorectal cancer (Lynch syndrome). His previous diseases included clipping of the anterior cerebral artery due to an aneurysm and appendectomy during his youth. Physical examination and rectal examination confirmed the presence of tumor formation starting at $1 \mathrm{~cm}$ from the anorectal line. Paraclinical test and chest X-ray showed no pathological changes. After a preoperative discussion of the multidisciplinary team, a decision was made to perform synchronous laparoscopic resection. The exact locations of the ports were carefully considered, as well as the innovative approach for extraction of anatomical structures through the perineal incision. The patient was placed on the surgical table in the Lloyd-Davies position. Using an open laparoscopy, a camera port was placed and 5 more trocars were inserted consecutively for placing the instruments $(4 \times 10 \mathrm{~mm}$ and $1 \times 5 \mathrm{~mm}$ ) (Figure 1).

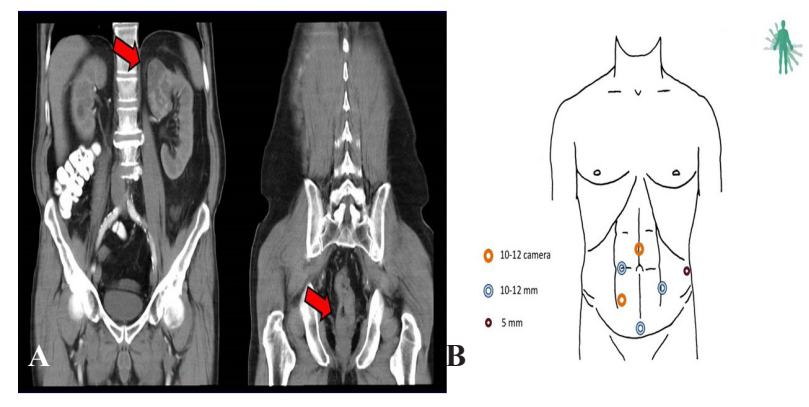

Figure 1: Computed Tomography With the Location of Tumors and the Position of Trocars.

A) CT of the Tumor Site; B) Trocars Position

First, high ligation of inferior mesenteric vessels was performed, and then the colon was mobilized along the line of Toldt. The course of the left ureter was ascertained and cranially followed to the level of the renal hilus. The left renal artery and vein were dissected, lifted on holders, and divided; using Hemo-Lok polymer clips. Then left nephrectomy was performed. Accordingly, the left ureter was clipped and divided, and the kidney was separated along
Gerota's fascia; using an ultrasound scalpel. Then, we continued with the second stage of the surgery by mobilizing the rectum as to the levator muscles, and making a total simultaneous mesorectal excision. The descending colon was divided $35 \mathrm{~cm}$ away from the tumor formation; using an endoscopic linear stapler.

We continued with the perineal stage of the surgery and the two specimens were extracted through the incision (Figure 2). In this way, no additional abdominal incision was required, and we did not find any similar case in our literature review.

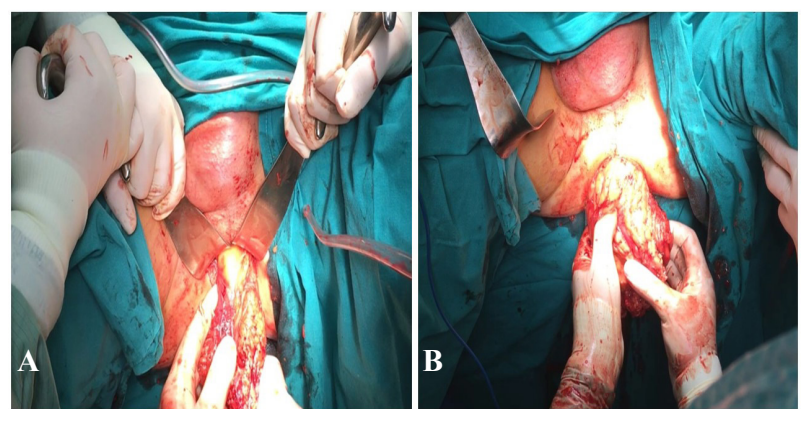

Figure 2: Extraction of Anatomical Resects Through the Perineal Incision

A) Rectum; B) Kidney

A definitive colostomy was performed at the typical place in the left abdominal quadrant. The surgical period was 330 minutes with a minimum blood loss of $150 \mathrm{~mL}$. Histopathological test results revealed moderately differentiated rectum adenocarcinoma (pT3NxM0V1G2). Additionally, moderately differentiated clear cell renal carcinoma $(6 \mathrm{~cm})$ was observed in left kidney (pT1bNxM0G2), Fuhrman grade II (Figure 3).

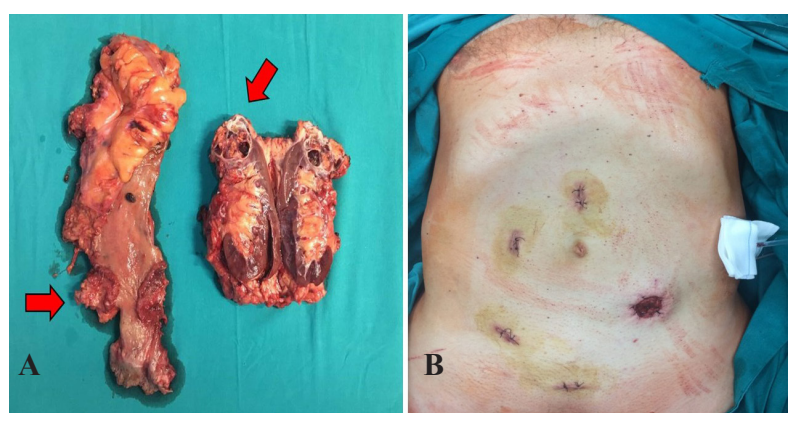

Figure 3: Synchronous Neoplasms After Extraction and the Cosmetic Effect of the Laparoscopic Surgery.

A) Anatomical Specimens; B) Cosmetic Effect After Resection

The postoperative period was uneventful with no evidence of complications, and food intake was initiated on the second postoperative day. The patient was discharged from the hospital on the 5th 
postoperative day. In the late postoperative period, the patient was not satisfied with his colostomy bag because it was not adequately secured. He was treated in the outpatient settings and no further hospitalization was required. Fifteen months after the surgery, a histologically proven lung cancer was diagnosed. There was no evidence of recurrence or metastatic colorectal cancer (CRC).

\section{DISCUSSION}

Synchronous renal neoplasms are supposed to affect $4.85 \%$ of patients with colorectal carcinoma [16], and according to some authors, their incidence rate is up to $5 \%$ [17]. The common use of preoperative diagnostic imaging, such as CT, MRI, and PET/CT allows for early diagnosing of coexisting tumors. Renal carcinoma is easily differentiated from other benign renal neoplasms on $\mathrm{CT}$ scans due to their specific enhancement and necrotic core [18]. Minimally invasive procedures in synchronous colorectal and renal tumors were first described in 2004 when Kim et al., performed the first handassisted surgery [5], and in the same year, Napolitano et al., performed the first laparoscopic resection [6]. The prevalence of male gender is $70.6 \%$ with a mean age of 68.4 years. Surgery duration ranged widely from 190 minutes in our second patient with synchronous laparoscopic resection to 460 minutes
(Table 1). The majority of interventions were performed in patients with homolateral tumors which are easier to be removed compared to contralateral tumors due to the overlapping of the two surgical fields. There was also a large difference in reported blood loss - from no blood loss to $1500 \mathrm{~mL}$. The duration of postoperative hospital stay also ranged widely from 5 days in our patient to 30 days. Because of the large differences between these parameters, we can say that the reliability of resections depends on the experience of the surgical team. In our case, the intervention was performed by a specific surgical team with a significant reduction in surgical duration and blood loss in the second procedure. By planning and preparing everything in advance and having in mind our experience in laparoscopic surgery, we were able to perform this difficult synchronous resection in a single stage. According to the literatures, simultaneous laparoscopic resection in synchronous tumors is a reliable and safe approach without further complications and is associated with a reduction in postoperative pain and hospital stay, quick recovery and normal daily activities, good cosmetic effect, and a relatively short surgical duration $[7,8,10,12-14]$. The benefits of this technique for our patient were early movement, feeding, and discharge after laparoscopic resection, as well as earlier initiation of adjuvant treatment. In

\begin{tabular}{|c|c|c|c|c|c|c|}
\hline & Age & Gender & $\begin{array}{c}\text { Surgery Duration, } \\
\text { min }\end{array}$ & $\begin{array}{l}\text { Blood Loss, } \\
\text { mL }\end{array}$ & $\begin{array}{l}\text { Postoperative Hospital } \\
\text { Length of Stay, days }\end{array}$ & $\begin{array}{c}\text { Ipsilateral or Contralateral } \\
\text { Resection }\end{array}$ \\
\hline Kim et al., [5] & 55 & male & 355 & 100 & 13 & $\mathrm{C}$ \\
\hline Napolitano et al., [6] & 74 & male & 270 & 300 & 8 & IP \\
\hline \multirow[t]{2}{*}{ NG et al., [7] } & 73 & male & 335 & 200 & 7 & $\mathrm{C}$ \\
\hline & 80 & male & 460 & 1500 & 21 & IP \\
\hline Veenstra et al., [8] & 70 & female & 210 & 100 & 8 & $\mathrm{C}$ \\
\hline \multirow[t]{2}{*}{ Campanati et al., [9] } & 68 & male & 450 & 100 & 14 & $\mathrm{C}$ \\
\hline & 70 & male & 380 & 150 & 8 & IP \\
\hline Fazzin et al., [10] & 79 & female & - & - & - & $\mathrm{C}$ \\
\hline Takahashi et al., [11] & 70 & female & 450 & 60 & 22 & IP \\
\hline \multirow[t]{4}{*}{ Arnau et al., [12] } & 63 & male & 300 & 0 & 6 & IP \\
\hline & 67 & male & 420 & 900 & 12 & $\mathrm{C}$ \\
\hline & 71 & male & - & - & 12 & IP \\
\hline & 62 & male & 360 & 300 & 30 & IP \\
\hline O'Sullivan et al., [13] & 73 & male & - & - & 10 & $\mathrm{C}$ \\
\hline Seunghun et al., [14] & 71 & female & 395 & 250 & 10 & IP \\
\hline \multirow[t]{2}{*}{ Takorov et al., [15] } & 63 & male & 330 & 150 & 5 & IP \\
\hline & 54 & female & 190 & 100 & 9 & IP \\
\hline
\end{tabular}

a Abbreviations: C, contralateral resection; IP, ipsilateral resection 
addition, better cosmetic results could be achieved as an advantage. However, it also has many disadvantages such as longer surgical duration, increased blood loss, increased cardiopulmonary risk, and more complicated surgical technique [14]. According to Simon, the open surgical approach is reliable and could prevent second surgical intervention, but it also has disadvantages such as large surgical incision for better visibility on various surgical fields and a higher rate of postoperative complications [7]. The postoperative outcomes are good concerning the complications and oncological follow-up as no metastases are observed [8]. Studies of laparoscopic approach in patients with colorectal carcinoma or renal cell carcinoma showed that longterm outcomes are very similar and comparable [9]. An important advantage is that it is a one-step and minimally invasive approach, preventing a second surgery and anesthesia, and reducing the discomfort for the patient and his/her relatives, while the prevention of a second hospitalization is also costeffective $[12,13]$. The exact locations of the ports should be carefully considered, and an additional port may be used in contralateral tumors for an adequate control [7,9]. An important requirement is to make resections in strict order. According to Simon, the colorectal resection should be made first, as there is better exposure of retroperitoneal urological organs and structures after the colon segments are removed, especially in patients with unilateral neoplasms [7]. Furthermore, the colon dilates 2-3 hours after the beginning of the operation and its resection becomes more difficult. In our case, high ligation of inferior mesenteric vessels was first performed, then the kidney was resected, and at the end, a colorectal resection was made with no evidence of colon distension. Depending on the case, resectates are usually extracted through laparotomy of various size. We made a perineal incision to extract both the amputated rectum and the resected kidney, thus an abdominal incision was not required. Our literature research did not show another similar surgical strategy for extraction of resectates.

We can say that the laparoscopic approach for resection of synchronous colorectal and renal neoplasms, is a reliable and safe method when performed by experienced surgeons in specialized medical centers. Contrast-enhanced imaging must be used in diagnosing colorectal tumors. Due to the low incidence of these two synchronous neoplasms, further multi-center studies should be conducted to assess their exact incidence rate and the methods for surgical and adjuvant therapy.

\section{ACKNOWLEDGEMENTS}

Not applicable.

\section{CONFLICTS OF INTEREST}

We have no competing interests.

\section{ETHICS APPROVAL}

A written informed consent was obtained from the patient before the study.

\section{REFERENCES}

1. Billroth T, Winiwarter Av. [The general surgical pathology and therapy]. Berlin: Georg Reimer; 1889. 1003 p.

2. Warren S. Multiple primary malignant tumors, a survey of the literature and a statistical study. Am. J. Cancer. 1932;16:1358-414.

3. Jayne DG, Thorpe HC, Copeland J, Quirke P, Brown JM, Guillou PJ. Five-year follow-up of the Medical Research Council CLASICC trial of laparoscopically assisted versus open surgery for colorectal cancer. Br J Surg. 2010;97(11):1638-45. DOI: 10.1002/bjs.7160 PMID: 20629110.

4. Zhu Q-L, Zheng M-H, Feng B, Lu A-G, Wang M-L, Li $\mathrm{J}-\mathrm{W}$, et al. Simultaneous laparoscopy-assisted low anterior resection and distal gastrectomy for synchronous carcinoma of rectum and stomach. World journal of gastroenterology. 2008;14(21):3435-7. DOI: 10.3748/wig.14.3435 PMID: 18528944 .

5. Kim SH, Park JY, Joh YG, Hoe HE. Simultaneous laparoscopic radical nephrectomy and laparoscopic sigmoidectomy for synchronous renal cell carcinoma and colonic adenocarcinoma. J Laparoendosc Adv Surg Tech A. 2004;14(3):179-81. DOI: 10.1089/1092642041255496 PMID: 15245672 .

6. Napolitano C, Santoro GA, Valvano L, Salvati V, Martorano M. Simultaneous totally laparoscopic radical nephrectomy and laparoscopic left hemicolectomy for synchronous renal and sigmoid colon carcinoma: report of a case. Int J Colorectal Dis. 2006;21(1):92-3. DOI: 10.1007/s00384004-0689-y PMID: 15668786.

7. Ng SS, Lee JF, Yiu RY, Li JC, Leung KL. Synchronous laparoscopic resection of colorectal and renal/adrenal neoplasms. Surg Laparosc Endosc Percutan Tech. 2007;17(4):283-6. DOI: 10.1097/SLE.0b013e31805ba827 PMID: 17710049 .

8. Veenstra GM, Fossion LM, de Laet K, Luijten AA. Synchronous Laparoscopic Radical Nephrectomy Left and Contralateral Right Hemicolectomy during the Same Endoscopic Procedure. ISRN Surg. 2011;2011:179456. DOI: 10.5402/2011/179456 PMID: 22084746. 
9. Luca C, Federico C, Marco L, Federico D, Gianfranco D, Daniel L, et al. Simultaneous Laparoscopic Nephrectomy and Colectomy for Synchronous Primary Malignancies: Surgical Techniques and the Results of Two Cases. 2013.

10. Fazzin M, Dellachiesa L, Resta G, Bandi M, Marino S, Anania G. One-stage laparoscopic procedure for a patient with bilateral colorectal tumours and renal carcinoma. G Chir. 2013;34(4):132-4. PMID: 23660167.

11. Takahashi M, Ichikawa R, Honjo K, Aoki J, Okazawa Y, Kojima Y, et al. Simultaneous Laparoscopic Colectomy and Nephrectomy for Synchronous Ascending Colon Cancer and Right Kidney Cancer: Report of a Case. Juntendo Medical Journal. 2014;60(4):345-8.

12. Martin Arnau AB, Ochoa Vargas C, Peña Gonzalez JA, Targarona Soler EM. Simultaneous colectomy and nephectomy in synchronic tumours. Cir Esp. 2015;93(4):266-8. DOI: 10.1016/j.ciresp.2014.04.006 PMID: 25022848 .

13. O’Sullivan M, Kearney DE, Giri SK, Coffey JC. Combined laparoscopic-assisted nephrectomy and complete mesocolic excision for synchronous renal and colon cancers. BMJ Case Rep. 2015;2015. DOI: 10.1136/bcr-2015-211681
PMID: 26420697.

14. Lee S, Lee S-H, Kim T, Baek S, Ahn B, Chung J, et al. Simultaneous Laparoscopic-Assisted Colorectal Resection and Nephrectomy. The Journal of Minimally Invasive Surgery. 2017;20(1):46-8. DOI: 10.7602/jmis.2017.20.1.46.

15. Takorov I, Trichkov T, Kostadinov R, Yakova M, Lukanova T, Mihaylov V, et al. Surgical Treatment of Synchronous Colorectal and Renal Neoplasms. Surg. Gastroenterol. 2019;24(5):241-6.

16. Halak M, Hazzan D, Kovacs Z, Shiloni E. Synchronous colorectal and renal carcinomas: a noteworthy clinical entity. Report of five cases. Dis Colon Rectum. 2000;43(9):13145. DOI: $10.1007 / \mathrm{bf02237444}$ PMID: 11005504.

17. Shiozawa M, Tsuchida K, Sugano N, Morinaga S, Akaike M, Sugimasa Y. A Clinical Study of Colorectal Cancer Patients with Other Primary Cancer. The Japanese Journal of Gastroenterological Surgery. 2007;40(9):1557-64. DOI: 10.5833 /jjgs.40.1557.

18. Heidenreich A, Ravery V. Preoperative imaging in renal cell cancer. World Journal of Urology. 2004;22(5):307-15. DOI: $10.1007 / \mathrm{s} 00345-004-0411-2$. 